\title{
Cerebrovascular stability during isoflurane anaesthesia in children
}

\author{
Bruno Bisonnette MD, Jeffrey E. Leon MD
}

The aims of this study were firstly, to determine the effect of various concentrations of isoflurane on cerebrovascular circulation and secondly, to examine the time-response characteristics of the drug on cerebral blood flow velocity in anaes. thetized children. Thirty-two ASA physical status I or II patients aged one to eight years and scheduled for urological surgery were studied. Anaesthesia was induced with thiopentone 5 $\mathrm{mg} \cdot \mathrm{kg}^{-1}$ and fentanyl $2 \mu \mathrm{g} \cdot \mathrm{kg}^{-1}$. Muscle relaxation was provided with vercuronium $0.1 \mathrm{mg} \cdot \mathrm{kg}^{-1}$. Tracheal intubation was performed in all cases. Anaesthesia was maintained with isoflurane in a mixture of air and oxygen to produce an inspired oxygen fraction $\left(\mathrm{FIO}_{2}\right)$ of 0.3 . Ventilation was adjusted to maintain normocapnia. A caudal or lumbar epidural catheter was inserted before skin incision and a continuous bupivacaine, without epinephrine, infusion established. During the first part of this study, the initial isoflurane concentration for 24 patients was randomized and age-adjusted to 0.5 MAC, 1.0 MAC, or 1.5 $M A C$. After steady-state was reached, the subsequent isoflurane $M A C$ concentration was randomized by either raising or lowering it from the initial concentration. In the second part of this study, the time-response effect of isoflurane was examined. Eight patients received 1.0 MAC isoflurane over 90 to $150 \mathrm{~min}$. Temperature, heart rate, and systolic blood pressure were

\section{Key words}

ANAESTHESIA: paediatric;

ANAESTHETICS, VOLATILE: isoflurane;

BRAIN: cerebral blood flow;

MEASUREMENT TECHNIQUES: Doppler, ultrasound

From the Department of Anaesthesia and the Research Institute, The Hospital for Sick Children, University of Toronto, Toronto, Ontario, Canada, M5G 1X8. Presented in part at the annual meeting of the American Society of Anesthesiology, Las Vegas, Nevada, October 19-23, 1990.

Address correspondence to: Dr.Bruno Bissonnette, Department of Anaesthesia, The Hospital for Sick Children, 555 University Avenue, Toronto, Ontario, Canada M5G 1X8.

Accepted for publication 16th September, 1991. unchanged throughout the study. Cerebral blood flow velocity (CBFV) and resistance index $(R I+)$, a measure of cerebrovascular resistance, were measured in the $M 1$ segment of the middle cerebral artery (MCA) with a $2 \mathrm{MHz}$ transcranial Doppler monitor. The CBFV and RI+ did not change when the initial isoflurane MAC concentration of either $0.5,1.0$, or $1.5 \mathrm{MAC}$, was varied. Furthermore, there was no change in $C B F V$ and $R I+$ when isoflurane was administered over time. This indicates that varying isoflurane MAC concentrations between 0.5 MAC and 1.5 MAC did not have any effect on cerebral circulation and that the administration of a constant concentration of isoflurane over time does not affect cerebral haemodynamic variables in anaesthetized healthy children.

La présente étude a pour but d'identifier l'effet de différentes concentrations d'isoflurane ainsi qu'examiner l'effet de la durée d'administration sur la circulation cérébrovasculaire de 32 enfants, âgés de un á huit ans, ASA I ou II, et anesthésie pour interventions urologiques. $L$ 'induction de l'anesthésie a été pratiquée à l'aide de thiopentone $5,0 \mathrm{mg} \cdot \mathrm{kg}^{-1}$ et de fentanyl 2,0 $\mu \mathrm{g} \cdot \mathrm{kg}^{-1}$. La relaxation musculaire était assurée à l'aide de vécuronium $0,1 \mathrm{mg} \cdot \mathrm{kg}^{-1}$ et la trachée intubée. Le maintien de l'anesthésie a été assuré à l'aide d'isoflurane dans un mélange d'air et d'oxygène de façon à produire une fraction inspirée d'oxygène $\left(\mathrm{FlO}_{2}\right)$ de 0,3. La ventilation mécanique était ajustée pour maintenir la normocapnie. Un bloc caudal ou un bloc lombaire épidural continu était administré avant le début de la chirurgie. Durant la première partie de cette étude, la concentration initiale d'isoflurane de 24 patients était ajustée de façon aléatoire, à $0,5,1,0$ ou 1,5 MAC, au tenant compte de la correction pour l'âge. Après avoir atteint l'état d'équilibre, la concentration d'isoflurane suivante était administrée, au hasard, d'une façon croissante ou décroisante par rapport à la concentration initiale. Durant la deuxième partie, nous avons examiné l'effet du temps surl'administration continue de 1,0 MAC d'isoflurane chez huit patients anesthésiés pour une durée de 90 à 150 minutes. La pression artérielle systolique, le rythme cardiaque et la température sont demeurés inchangés durant toute la période étudiée. La vélocité du débit sanguin cérébral (CBFV) ainsi que l'index de résistance cérébrovasculaire $(R I+)$ de l'artère cérébrale moyenne (MCA) ont été mesurés avec l'aide d'un moniteur Doppler transcranien utilisant une fréquence de 
$2 M H z$. La CBFV et le RI+ n'ont pas changé lorsque la concentration initiale d'isoflurane $(0,5,1,0$, ou 1,5 MAC), était augmentée ou diminuée pour compléter la boucle. De plus, nous n'avons pas observé de changement de la CBFV et du RI+ lorsque l'isoflurane était administré pour une longue période de temps. Ces résultats démontrent que les différentes concentrations d'isoflurane n'affectent pas la circulation cérébrovasculaire et que la durée d'administration d'une concentration fixe d'isoflurane ne modifie pas certaines des variables hémodynamiques cérébrales lors de l'anesthésie chez des enfants sains.

Transcranial Doppler studies have been used for noninvasive diagnosis for $25 \mathrm{yrs}$. For more than a decade they have been used to estimate cerebral blood flow (CBF) in infants and children with open fontanelles.' In 1982, Aaslid et al. described the use of a 1-2 MHz doppler which could measure CBF in adults non-invasively. ${ }^{2}$ These modifications have enabled reliable measurements of MCA flow velocity through the temporal bone in anaesthetized children. ${ }^{3}$

Halothane, a commonly used inhalational agent in paediatric neuroanaesthesia was shown by Lazzell $e t$ al. to cause an increase in cerebral blood flow velocity (CBFV) as the inspired concentration was increased. ${ }^{4}$ This increase in CBFV was thought to be due to a simultaneous decrease in cerebrovascular resistance suggesting an abolition of cerebral autoregulation. The same investigators have shown that halothane exhibits a 30 to $\mathbf{4 5}$ min delay in retum of CBFV to baseline values when the halothane concentration was decreased from 1.5 MAC to 0.2 MAC; this has been termed an hysteresis phenomenon. ${ }^{5}$

Isoflurane is now considered the inhalational agent of choice in neuroanaesthesia. ${ }^{6}$ It causes less cerebral vasodilatation and brain surface protrusion than halothane or ethrane at equipotent concentrations but controversy exists regarding its effect on CBF at different concentrations. ${ }^{7-8}$ An animal study by MacPherson et al. demonstrated that $1 \mathrm{MAC}$ isoflurane did not change CBF whereas 2 MAC isoflurane caused substantial hyperaemia. ${ }^{9}$ Vanaken et al. reported that cerebral blood flow changed passively with blood pressure at an isoflurane concentration greater than 1 MAC. ${ }^{10}$ Gelman et al. using a dog model showed that 1 MAC and 2 MAC isoflurane caused vasodilatation of the cerebral vasculature to a greater degree than halothane. ${ }^{11}$ Results of adult human studies in which isoflurane concentrations up to 1.5 MAC were used showed that CBF did not increase. ${ }^{8}$ The effects of isoflurane on the CBFV in healthy children have not been reported previously.

Further controversy exists regarding the effect of isoflurane on CBF over time. Turner et al. demonstrated that it produced cerebral vasodilatation in dogs but that this effect diminished after two hours. ${ }^{12}$ MacPherson et al. showed that 1.0 MAC isoflurane anaesthesia in normocapnic dogs caused a decrease in CBF over time. ${ }^{13}$ However, a more recent study by Roald et al. showed that, in dogs, there was no change in CBF during three to four hours of steady-state $1 \%$ isoflurane anaesthesia. ${ }^{14}$ The effect of prolonged isoflurane administration on CBF in human remains unknown.

This study was designed to determine: (1) the cerebrovascular response of increasing and decreasing the concentration of isoflurane between 0.5 to $1.5 \mathrm{MAC}$, and (2) to examine the time-response effect of isoflurane on CBFV and $R I+$ in healthy children.

\section{Methods}

\section{Practical Procedure}

Following approval from the Human Subjects Review Committee, informed written consent was obtained from the parents of 32 ASA physical status I or II children scheduled for elective urological surgery. All children were fasting and unpremedicated. Patients with cardiac or neurological disease and patients with a contraindication to regional anaesthesia were excluded. All patients were supine and horizontal throughout the study.

Patients were monitored in an appropriate manner for the induction of anaesthesia. Anaesthesia was induced with intravenous thiopentone $5 \mathrm{mg} \cdot \mathrm{kg}^{-1}$, and fentanyl 2 $\mu \mathrm{g} \cdot \mathrm{kg}^{-1}$ followed by vecuronium $0.1 \mathrm{mg} \cdot \mathrm{kg}^{-1}$ to facilitate tracheal intubation. The lungs were ventilated with air $/ \mathrm{O}_{2}$ by intermittent positive pressure at peak inspiratory pressures of $20-25 \mathrm{~cm} \mathrm{H}_{2} \mathrm{O}$ and an end-expiratory pressure of zero. Ventilation was adjusted to achieve normocapnia. Fresh gas flow was maintained at a constant rate throughout the study to avoid changes in intrathoracic pressure. Anaesthesia was maintained with isoflurane in a mixture of air and oxygen to produce an $\mathrm{FIO}_{2}$ of 0.3 . Muscle relaxation was maintained with vecuronium $0.05 \mathrm{mg} \cdot \mathrm{kg}^{-1}$. A continuous caudal or lumbar epidural block using $0.25 \%$ bupivacaine without epinephrine was administered to all patients before incision. Normothermia was maintained using a Humid-Vent 1 (Gibeck-Dryden Corporation, Indianapolis, Indiana, USA) ${ }^{15-16}$ and a warming blanket. Lactated Ringer's solution $\left(5 \mathrm{ml} \cdot \mathrm{kg}^{-1}\right)$ was administered over the initial $15 \mathrm{~min}$ to replace the fluid deficit with a further $2 \mathrm{ml} \cdot \mathrm{kg}^{-1} \cdot \mathrm{hr}^{-1}$ allowed for maintenance. Additional fluid was given as needed to replace surgical losses.

\section{Experimental protocol}

Part I: In the first part of the study, 24 children were divided into three groups according to their initial isoflurane concentration. Each group received, initially, a 
TABLE Data summary

\begin{tabular}{lcccccccc}
\hline & \multicolumn{1}{l}{ Isoflurane MAC } & & & \\
\cline { 2 - 8 } Variables & $0.5^{a}$ & $0.5^{b}$ & $1.0^{a}$ & $1.0^{b}$ & $1.5^{a}$ & $1.5^{b}$ & $P^{a}$ & $p^{b}$ \\
\hline HR $\left(\right.$ beats $\left.\cdot \mathrm{min}^{-1}\right)$ & $101 \pm 20$ & $103 \pm 22$ & $100 \pm 24$ & $100 \pm 21$ & $104 \pm 23$ & $103 \pm 21$ & $\mathrm{~ns}$ & $\mathrm{~ns}$ \\
SABP $(\mathrm{mmHg})$ & $89 \pm 11$ & $91 \pm 11$ & $88 \pm 10$ & $89 \pm 12$ & $88 \pm 7$ & $93 \pm 10$ & $\mathrm{~ns}$ & $\mathrm{~ns}$ \\
PETCO $(\mathrm{mmHg})$ & $37 \pm 3$ & $39 \pm 2$ & $38 \pm 2$ & $37 \pm 2$ & $38 \pm 3$ & $37 \pm 2$ & $\mathrm{~ns}$ & $\mathrm{~ns}$ \\
TEMP $\left({ }^{\circ} \mathrm{C}\right)$ & $37.0 \pm 0.2$ & $36.8 \pm 0.1$ & $36.9 \pm 0.2$ & $36.7 \pm 0.2$ & $36.9 \pm 0.2$ & $36.7 \pm 0.2$ & $\mathrm{~ns}$ & $\mathrm{~ns}$ \\
$\mathrm{AP}\left(\mathrm{cm} \mathrm{H}_{2} \mathrm{O}\right)$ & $19 \pm 3$ & $20 \pm 2$ & $20 \pm 2$ & $20 \pm 3$ & $22 \pm 2$ & $21 \pm 2$ & $\mathrm{~ns}$ & $\mathrm{~ns}$ \\
$\mathrm{SaO}(\%)$ & $98 \pm 2$ & $99 \pm 2$ & $99 \pm 2$ & $99 \pm 1$ & $97 \pm 2$ & $98 \pm 3$ & $\mathrm{~ns}$ & $\mathrm{~ns}$ \\
$\mathrm{CBFV}\left(\mathrm{cm} \cdot \mathrm{sec}^{-1}\right)$ & $130.6 \pm 25.7$ & $132.6 \pm 15.4$ & $134.9 \pm 25.3$ & $133.5 \pm 23.2$ & $133.5 \pm 28.8$ & $134.9 \pm 20.4$ & $\mathrm{~ns}$ & $\mathrm{~ns}$ \\
$\mathrm{RI}+$ & $0.63 \pm 0.07$ & $0.60 \pm 0.05$ & $0.63 \pm 0.06$ & $0.61 \pm 0.05$ & $0.64 \pm 0.05$ & $0.63 \pm 0.08$ & $\mathrm{~ns}$ & $\mathrm{~ns}$ \\
\hline
\end{tabular}

All values are mean $(\mathrm{SD})$.

Abbreviations: $\mathrm{HR}$, heart rate; SABP, systolic arterial blood pressure; $\mathrm{PETCO}_{2}$, end-tidal $\mathrm{CO}_{2} ; \mathrm{TEMP}$, temperature; AP, airway pressure; $\mathrm{SaO}_{2}$, arterial oxygen saturation; CBFV, cerebral blood flow velocity; RI+, cerebrovascular resistance.

$M C^{a}$ values represent the initial minimum alveolar concentration from which isoflurane was subsequently either raised or lowered.

$M A C^{b}$ values represent the final concentration.

${ }^{\mathrm{B}} \mathrm{P}$ values are obtained by paired $\mathrm{t}$ test comparing the initial and final concentration.

${ }^{b} \mathrm{P}$ values are obtained by repeated-measures of variance and Student-Newman-Keuls for multiple comparisons within all isoflurane MACs.

randomized end-tidal concentration of isoflurane of either 0.5 MAC, 1.0 MAC or 1.5 MAC. After three measurements of CBFV and RI+ were obtained at the initial $M A C$, the patients then received the subsequent isoflurane concentrations which were either raised or lowered in random manner after which the initial concentration was resumed. Transcranial Doppler measurements were recorded for each isoflurane MAC after allowing $15 \mathrm{~min}$ to reach steady-state. Three visual displays to systolic and diastolic flow velocities (CBFV) and RI+ in the MCA were obtained at one minute intervals during periods of haemodynamic stability at each isoflurane MAC concentration value.

Part II: In the second part of the study, the time-response of isoflurane on CBFV and RI + was measured in eight children. All patients received a steady-state 1.0 MAC isoflurane anaesthesia over a period of $90-180 \mathrm{~min}$. Three measurements of CBFV and RI+ were recorded every $15 \mathrm{~min}$.

Systolic arterial blood pressure, heart rate, arterial oxygen saturation, and inspired $\mathrm{O}_{2}$ fractions were recorded simultaneously with the measurements of CBFV and RI+ throughout both segments of the study period. The endtidal concentrations of isoflurane and $\mathrm{CO}_{2}$ were measured from the distal end of the tracheal tube and analyzed with a calibrated Puritan-Bennett Datex 254 airway gas monitor (Datex Instrumentation Corporation, Helsinki, Finland). ${ }^{17}$ The gas monitor was calibrated using a reference gas mixture before each use. The CBFV and RI+ were obtained from the continuous recording of the Ml segment of the middle cerebral artery using a transcranial Doppler sonography monitor (Transpect TCD Medasonics, Fremont, $\mathrm{CA}) .{ }^{18}$

\section{Statistical analysis}

The mean \pm standard deviation (SD) for age, weight, systolic arterial blood pressure, heart rate, temperature, arterial $\mathrm{O}_{2}$ saturation, and end-tidal $\mathrm{CO}_{2}$ was determined. The analysis of each TCD file was done by an investigator (BB) unaware of the isoflurane concentration and the sequences at which each file were recorded. Based on a previous investigation, ${ }^{19-21}$ a sample size of eight patients per initial isoflurane MAC concentration was determined by power analysis assuming $\mathrm{a}=0.05, \mathrm{~b}=0.2$, and $\mathrm{a}$ difference in CBF between 0.5 MAC and 1.5 MAC of $30 \%$. Paired $t$ test was used to compare the initial and final isoflurane concentrations. Repeated-measures analysis of variance and the Student-Newman-Keuls test for multiple comparisons were used to determine statistical significance difference at each isoflurane MAC concentration for CBFV, RI+, HR, systolic arterial blood pressure, temperature, arterial $\mathrm{O}_{2}$ saturation, and end-tidal $\mathrm{CO}_{2}$. A $P<0.05$ was accepted to express statistical significance.

\section{Results}

Part I: The mean \pm SD age and weight of the 24 children were $46.3 \pm 27.3$ months and $18.5 \pm 4.8 \mathrm{~kg}$, respectively. Heart rate, systolic arterial blood pressure, arterial oxygen saturation, temperature and end-tidal $\mathrm{CO}_{2}$ did not change during the study period (Table). Doppler recordings of the CBFV in the MCA and calculations of RI+ values were completed in all children, at 0.5 MAC, 1.0 MAC, and 1.5 MAC isoflurane. The CBFV and RI+ did not change when the initial isoflurane MAC concentration of either $0.5,1.0$, or $1.5 \mathrm{MAC}$ was varied (Figure 1).

Part II: The mean \pm SD age and weight of the eight children were $40.2 \pm 31.5 \mathrm{mo}$ and $15.5 \pm 6.2 \mathrm{~kg}$, respective- 


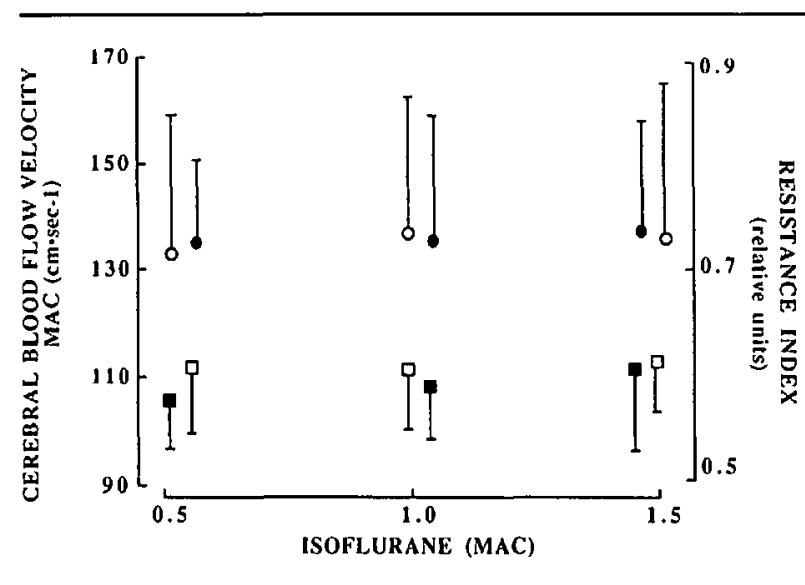

FIGURE 1 Cerebral blood flow velocity and cerebrovascular resistance at three MAC values. Cerebral blood flow velocity at (0.5-1.01.5 MAC) (0) and (1.5-1.0-0.5 MAC) (0) isoflurane was measured. The resistance index at $(0.5-1.0-1.5 \mathrm{MAC})$ (D) and (1.5-1.0-0.5 MAC) ( $\square$ ) isoflurane was measured.

ly. All eight patients were given a steady-state $1.0 \mathrm{MAC}$ isoflurane for 90 to $150 \mathrm{~min}$ and there was no change in CBFV over time (Figure 2). There were no complications from the use of the TCD in this study.

\section{Discussion}

The results of this study demonstrate that varying the isoflurane minimum alveolar concentration did not produce any effect on CBFV and RI+ in healthy anaesthetized children. Using the same methodology, Lazzell et al. showed that CBFV increased when the halothane concentration was increased between 0.5 MAC and 1.5 MAC. ${ }^{4}$ In addition, it was observed that halothane caused a 30 to 45 min delay in the return of CBFV to the baseline value when the halothane concentration was decreased from 1.5 MAC to 0.2 MAC. 5

In this study it was not possible to show a change in CBFV and $\mathrm{RI}+$ at either $0.5,1.0$, or 1.5 MAC isoflurane. Thus, isoflurane did not exhibit the hysteresis phenomenon of CBFV and RI+ previously described using halothane in similar experimental conditions. ${ }^{5}$

The results of this study are in agreement with the conclusions of Eintrei et al. who measured CBF after applying small doses of ${ }^{133}$ xenon on the exposed cortex and showed that there was no dose-dependent relationship in adult humans anaesthetized with isoflurane up to 1.5 MAC. ${ }^{8}$ Algostsson et al. studied the effects of isoflurane on human cerebral blood flow and reported that isoflurane did not change CBF whereas halothane caused an increase of $36 \% .{ }^{22}$ Madsen et al. reported the absence of any changes in CBF in adult humans undergoing craniotomy for supratentorial cerebral tumour. ${ }^{23}$ Todd et al. using a cat model reported that at three concentrations of $0.5,1.0$, and

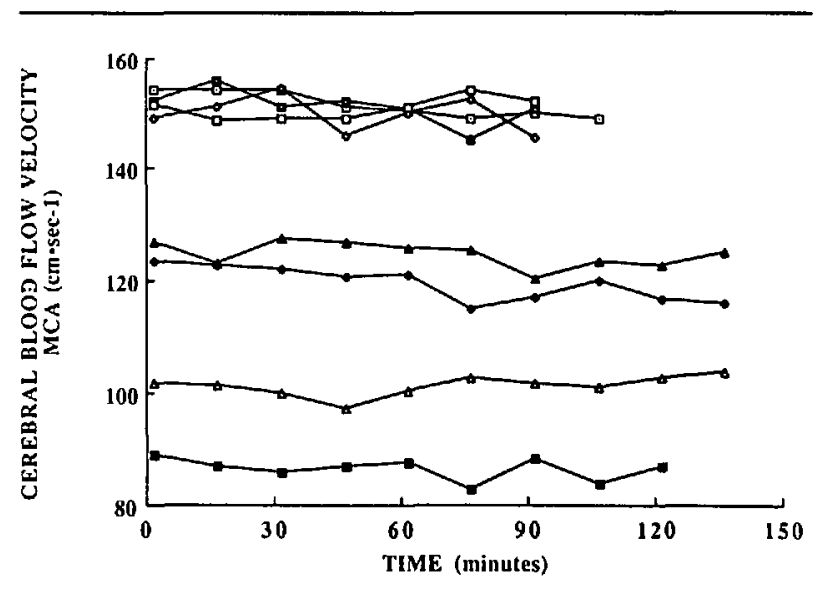

FIGURE 2 Cerebral blood flow velocity measured at 1.0 MAC isoflurane for 90 to $150 \mathrm{~min}$ in eight patients.

1.5 MAC, isoflurane in the presence of $\mathrm{N}_{2} \mathrm{O}$ had no effect on $\mathrm{CBF}$ and produced smaller decreases in cerebrovascular resistance than halothane. ${ }^{24}$ However, MacPherson et al. using a dog model showed that increasing isoflurane concentration produced a non-autoregulated cerebral vascular bed. ${ }^{13}$ Cucchiara et al. reported that canine cerebral blood flow increased by $33 \%$ and $63 \%$ at $1.4 \%$ and $2.4 \%$ concentrations, respectively. ${ }^{20}$ They demonstrated that this effect was due to a decrease in cerebrovascular resistance and suggested that isoflurane was similar to halothane. Another explanation might be that the cerebral vasodilatation generated by isoflurane is counteracted by the decrease in mean arterial pressure. However, in the present investigation none of the children experienced any changes in MAP with the increase in isoflurane concentration. Furthermore, the absence of any change in cerbrovascular resistance suggests that isoflurane did not dilate the cerebral vessel studied.

In order to examine the contribution of time on the effect of isoflurane on the CBFV and RI+, we observed 1.0 MAC isoflurane anaesthesia over time in eight patients. We found that 1.0 MAC isoflurane administered for 90 to 150 min did not affect CBFV or RI+. These findings are consistent with those of Roald et al. who showed, using a very complex model, that $1 \%$ isoflurane had no effect on CBF during three to four hours of isoflurane anaesthesia. ${ }^{14}$ However, Turner $e t$ al. reported in a dog model that CBF measured with $15 \mu \mathrm{m}$ microspheres two hours after the induction isoflurane-nitrous oxide anaesthesia was significantly increased in all regions of the brain. ${ }^{12}$ McPherson et al. showed that normocapnic CBF decreased over time with $1.4 \%$ isoflurane. ${ }^{13}$

In this study there are some methodological considerations that merit comment. The fact that isoflurane did not cause measurable change in the CBFV does not exclude 
the possibility of a specific cerebral vasodilator property or an inability of our technology to detect such a change. Manohar $e t$ al. administered isoflurane to swine and found that 1.0 MAC isoflurane increased brain stem and cerebellar blood flow without increasing hemispheric $\mathrm{CBF}^{26}$ However, they observed that $1.5 \mathrm{MAC}$ isoflurane increased hemispheric flow. In this study the Doppler monitor was used to measure flow velocity in a single vessel, the middle cerebral artery (MCA). The MCA is the largest branch of the basal cerebral artery providing some $70 \%$ of total blood flow of the ipsilateral hemisphere. ${ }^{27}$ It is likely that any modification in cerebral blood flow velocity generated by isoflurane would be detectable from this important basal cerebral vessel.

With regard to the specificity of the transcranial Doppler, there are several assumptions underlying the relationship between CBFV and cerebral blood flow that have been discussed in previous publications. ${ }^{18}$ Other potential considerations in the measurement of CBFV are errors based on the physics of ultrasound waves and Doppler instruments. The maximum error may be attributed to changes related to the angle of insonation and the Doppler resolution. Studies performed on cadavers showed that the M1 segment of the MCA can be insonated through the temporal windows with an angle of less than 20 degrees. $^{28}$ Because Doppler shift is proportional to the cosine of the angle and the CBFV is calculated from the shift in the ultrasound velocity, the maximum error generated by this variation is $7 \%$. The individual variability as measured by the coefficient of variation was $4 \%$ which was less than the error due to the angle of insonation suggesting that we were within the limit for every patient. It may be that the resolution of the Doppler monitor is not good enough to identify small changes in CBFV. The Doppler resolution is determined by the frequency of the transducer (carrier frequency) and the angle at which the Doppler beam is used. The transpect TCD high-pass filters are active between 100 and $150 \mathrm{~Hz}$ which, accompanied with minimal angle of insonation, translates to a minimal display velocity of $3 \mathrm{~cm} \cdot \mathrm{sec}^{-1}$. If any changes of this magnitude in CBFV had been observed among the three different minimum alveolar concentrations studied, it only helps to confirm the lack of effect of isoflurane on cerebral vasculature.

The time constant for the equilibration of brain grey matter and blood for isoflurane is three minutes. ${ }^{29} \mathrm{We}$ waited $15 \mathrm{~min}$ to achieve steady-state conditions with isoflurane within the brain. If these equilibrium periods had been inadequate, then CBFV would have changed between the first and third measurements in any particular patient for any set of conditions. Our data showed no consistent changes between the first and third measurements. The calculated coefficients of variation were 5.3\% for the CBFV and $6.6 \%$ for RI+ measurements. Thus, the equilibrium periods used for isoflurane produced steadystate conditions within the basal cerebral arteries of the brain.

We estimated the arterial $\mathrm{PCO}_{2}$ by measuring the $\mathrm{PETCO}_{2}$ at the distal tip of the endotracheal tube. Previous studies have shown that both single-breath and continuous distal $\mathrm{PETCO}_{2}$ closely approximates $\mathrm{PaCO}_{2}$ in healthy infants and children. ${ }^{17,30}$

Intrathoracic pressure affects cerebral perfusion pressure by its indirect effect on cerebral venous pressure. We maintained a constant mean intrathoracic pressure during each study to preclude the effect of changes in ventilation on CBFV. The $\mathrm{PETCO}_{2}$ was adjusted to achieve normocapnia after which the ventilator settings were not modified. Thus, the observed changes in CBFV could not be attributed to changes in intrathoracic pressure.

Individual variability could introduce error into our measurements. Age is a major determinant of the $\mathrm{CBFV} .{ }^{31}$ There is a linear increase in CBFV from birth to the age of two months; thereafter it increases more slowly to reach its peak value at six years of age and then decreases slowly to $70 \%$ of this peak at age 16 . The CBFV decreases an additional $20 \%$ between 20 and $60 \mathrm{yr}^{32,33}$ In this study, the patient age range was one to eight years which suggest that the large standard deviations are probably related to these physiological variations rather than the pharmacological effect of isoflurane. All patients had similar haemoglobin concentrations $\left(12-14 \mathrm{mg} \cdot \mathrm{dl}^{-1}\right)$, metabolic demands (normothermia was maintained), and haemodynamic profiles (no change in blood pressure or heart rate at any time), thereby reducing the contributions of these factors on the variability observed.

We concluded that cerebral blood flow velocity and cerebrovascular resistance are maintained at a constant levels during isoflurane anaesthesia between $0.5 \mathrm{MAC}$ and 1.5 MAC. In addition, the effect of the prolonged administration of 1.0 MAC isoflurane failed to show a timeresponse effect on cerebral circulation. Can these observations be applied to a patient with increased intracranial pressure? Lazzell et al. using the same anaesthetic technique, showed that in children with acutely elevated intracranial pressure changes in CBFV and RI+ were related to surgical decompression and not to isoflurane. ${ }^{34}$ The degree of impairment observed was dependent on the initial intracranial pressure and its position on the intracranial elastance curve. The clinical importance of these observations in patients with increased intracranial pressure would suggest that cerebrovascular stability conferred by isoflurane between 0.5 MAC and 1.0 MAC may make it the drug of choice in these circumstances. Moreover, the lack of a dose-dependent relationship over time of 1.0 MAC isoflurane on the cerebral vasculature of 
anaesthetized healthy children adds further to its suitability in neurosurgical patients. The speculative nature of this conclusion needs to be confirmed by further investigations where the effects of higher MAC multiples of isoflurane on cerebrovascular circulation and the effect of isoflurane on patients with reduction in cerebral compliance have yet to be investigated.

\section{Acknowledgements}

The authors wish to sincerely thank Dr. J.E.S. Relton for his enthusiasm and help in the preparation of this manuscript. The authors greatly appreciate Drs. B. Churchill, G. McLorie, T. Khoury, and the Fellows, Residents and Nurses of the Division of Urology for their patience and cooperation in the performance of this study. We thank Medasonics Incorporated, Fremont CA for providing a Transcranial Doppler to undertake this study.

\section{References}

1 Bada HS, Hajjar W, Chua C, Sumner DS. Non-invasive diagnosis of neonatal asphyxia and intraventricular hemorrhage by Doppler ultrasound. J Pediatr 1979; 95: 775-9.

2 Aaslid R, Markwalder TM, Nornes $H$. Noninvasive transcranial Doppler ultrasound recording of flow velocity in basal cerebral arteries. J Neurosung 1982; 57: 769-74.

3 Pilato MA, Bissonnette B, Lerman J. Cranial duplex sonography: effect of $\mathrm{PCO}_{2}$ on the velocity of blood in the cerebral vasculature of anaesthetized children. Can J Anaesth 1991; 38: 37-42.

4 Lazzell VA, Bissonnette B. Pilato MA, Lerman J. Transcranial doppler sonography: effect of halothane on cerebral hemodynamics in children. Anesthesiology 1989; 71: A332.

5 Lazzells V, Bissonnette B, Lerman J. Does hysteresis exist under halothane anesthesia? Anesthesiology 1989; 71 : A327.

6 Michenfelder JD, Sundt TM, Fode N, Sharborough $F W$. Isoflurane when compared to enflurane and halothane decreases the frequency of cerebral ischemia during carotid endarterectomy. Anesthesiology 1987; 67: 336-40.

7 Murphy PL, Kennell EM, Johnstone RE et al. The effects of enflurane, isoflurane and halothane on cerebral blood flow and metabolism in man. Anesthesiology 74; 41: A62.

8 Eintrei $C$, Leszniewski W, Carlsson $C$. Local application of ${ }^{133}$ xenon for measurement of regional cerebral blood flow (ICBF) during halothane, enflurane, isoflurane anesthesia in humans. Anesthesiology 1985; 63: 391-4.

9 McPherson RW, Brian JE, Traystman RJ. Cerebrovascular responsiveness to carbon dioxide in dogs with $1.4 \%$ and $2.8 \%$ isoflurane. Anesthesiology 1989; 70: 843-50.

10 VanAken J. Brussel T, Fitch W, Haussen GM. Hypotension induced by isoflurane: its effect on blood flow and cerebral autoregulation. Cah Anesthesiol 1986; 34: 47-53.
11 Gelman S, Fowler KC, Smith LR. Regional blood flow during isoflurane and halothane anesthesia. Anesth Analg 1984; 63: 557-65.

12 Turner DM, Kassell NF, Sasaki T et al. Time-dependent changes in cerebral and cardiovascular parameters in isoflurane-nitrous oxide-anesthetized dogs. Neurosurgery 1984; 14: 135-41.

13 McPherson RW, Traystman J. Effect of time on cerebrovascular responsivity to $\mathrm{PACO}_{2}$ during isoflurane anesthesia. Anesthesiology 1989; 71: A105.

14 Roald LK, Forsman M, Steen PA. The effects of prolonged isoflurane anaesthesia on cerebral blood flow and metabolism in the dog. Acta Anaesthesiol Scan 1989; 33: 210-3.

15 Bissonnette B, Sessler DI, LaFlamme P. Passive and active inspired gas humidification in infants and children. Anesthesiology 1989; 71: 381-4.

16 Bissonnette B, Sessler DI. Passive or active inspired gas humidification increases thermal steady-state temperatures in anesthetized infants. Anesth Analg 1989; 69: 783-9.

17 Badgwell JM, McLeod ME, Lerman J, Creighton $R E$. End-tidal $\mathrm{PCO}_{2}$ measurements sampled at the distal and proximal ends of the endotracheal tube in infants and children. Anesth Analg 1987; 66: 950-64.

18 Leon JE, Bissonnette $B$. Cerebrovascular responses to carbon dioxide in children anaesthetized with halothane and isoflurane. Can J Anaesth 1991; 38: 817-25.

19 Adams RW, Cucchiara RF, Gronert GA, Messick JM, Michenfelder $J D$. Isoflurane and cerebrospinal fluid pressure in neurosurgical patients. Anesthesiology 1981; 54: 97-9.

20 Cucchiara RF, Theye Ra, Michenfelder JD. The effects of isoflurane on canine cerebral metabolism and blood flow. Anesthesiology 1974; 40: 571-4.

21 Stullken EH Jr, Milde JH, Michenfelder JD, Tinker JH. The nonlinear responses of cerebral metabolism to low concentrations of halothane, enflurane, isoflurane, and thiopental. Anesthesiology 1977; 46: 28-34.

22 Algotsson L, Messeter K, Nordström CH, Ryding E. Cerebral blood flow and oxygen consumption during isoflurane and halothane anesthesia in man. Acta Anaesthesiol Scand 1988 ; 32: 15-20.

23 Madsen JB, Cold GE, Hansen ES, Bardrum B. Cerebral blood flow, cerebral metabolic rate of oxygen and relative $\mathrm{CO}_{2}$-reactivity during craniotomy for supratentorial cerebral tumours in halothane anaesthesia. A dose-response study. Acta Anaesthsiol Scand 1987; 31: 151-7.

24 Todd MM, Drummond JC. A comparison of the cerebrovascular and metabolic effects of halothane and isoflurane in the cat. Anesthesiology 1984; 60: 276-82.

25 Hales JR, Cliff WJ. Direct observations of the behavior of microspheres in microvasculature. Bibl Anat 1977; 15: 87-91. 
26 Manohar M, Goetz TE. Cerebral, renal, adrenal, intestinal and pancreatic circulation in conscious ponies and during $1.0,1.5$, and 20 minimal alveolar concentrations of halothane- $\mathrm{O}_{2}$ anesthesia. Am J Vet Res 46; 12: 2492-7.

27 Carpenter $M B$, Sutin J. Human Neuroanatomy. 8th ed. Baltimore: Williams \& Wilkins, 1983; 872.

29 Eger El. Uptake of Inhaled Anesthetics: The alveolar to inspired anaesthetic difference: In Eger EI (Ed.). Anaesthetic Uptake and Action. Baltimore: Williams and Wilkins Inc., 1981: 88-94.

30 Bissonnette $B$, Lerman $J$. Single breath end-tidal $\mathrm{CO}_{2}$ estimate of arterial $\mathrm{PCO}_{2}$ in infants and children. Can J Anaesth 1989; 36: 2-4.

31 Bode $H$. Methods: Recording Technique. In: Bode H (Ed.). Paediatric Applications of Transcranial Doppler Sonography. New York: Springer-Verlag, 1988: 21-2.

32 Gray PH, Griffin EA, Drumm JE, Fitzgerald DE, Duignan $N M$. Continuous wave doppler ultrasound evaluation of cerebral blood flow in neonates. Arch Dis Child 1983; 58 : 677-81.

33 Arnolds BJ, Von Reutern GM. Transcranial Doppler Sonography. Examination technique and normal reference values. Ultrasound Med Biol 1986; 12: 115-23.

34 Lazzell VA, Bissonnette B, Drake JM, Lerman J. Transcranial doppler sonography: cereral hemodynamics after stepwise decreases in intracranial pressure in children with raised intracranial pressure. Anesthesiology 1989; 71 :

A100. 